\title{
Impact of Efficient DC loads: LED Lighting as Equivalent to Large Power Generation Plant
}

\author{
J.A. Qureshi, T.T. Lie \\ Electrical and Electronics Engineering \\ Auckland University of Technology \\ Auckland, New Zealand \\ jqureshi@,ieee.org, tek.lie@,aut.ac.nz
}

\author{
R. Hasan \\ Engro Power and Polymers Ltd, \\ Karachi, Pakistan \\ rabeeahasan1@gmail.com
}

\author{
T. Mujtaba \\ K-Electric Ltd. \\ Karachi, Pakistan \\ toobamujtaba@ieee.org
}

\begin{abstract}
Power shortage is one of the major challenges that is being encountered globally. Conservation of energy is an effective and economical solution to cater the increasing electricity demand as compared to electricity generation. Increasing generation has a profound impact on the excessive emission of greenhouse gases (GHGs). In this paper, Light Emitting Diode (LED) lamps are presented as an efficient DC loads to influence the electricity demand curves. The application of the tool is carried out on the monthly demand curves obtained from National Electric Power Regulation Authority (NEPRA) of Pakistan. A considerable decline in the monthly power demand is observed by implementing the suggested solution which is equivalent to a large power generation plant. The solution presented is also an effective way to cater the gap between electricity supply and demand. The proposed recommendation for modern lighting can solve the power issue by taking care of environment contamination and would be a vital step towards a pollution free, ecological planet. Similar effects can be observed for other efficient DC loads.
\end{abstract}

Keywords- Energy Conservation, Energy Efficiency, LED lighting

\section{INTRODUCTION}

Due to the advent of modern technology and increased power demand, the developing countries of the world are facing serious energy crisis [1]. The replacement of manual machines with automatic equipment to raise living standards is significantly contributing to the power demand. The augmented cost of generation and the harmful effects of Green House Gases (GHGs) make generation of electricity an inappropriate solution for this world [2, 3]. Electric Supply Companies (ESCs) in Pakistan are unable to meet the increased electricity demand in financial limits and only left with load shedding as demand side solution. Power deficit in Pakistan has reached to an alarming value of 6000MW [4]. This shortfall has led to economic and social instability in the country [5].

Many techniques have been designed in order to manipulate the consumer demand according to the generation capacity [6, 7]. Demand Side Management (DSM) was suggested to shift the peak ripples from the demand curve temporarily $[8,9]$. DSM solutions require constant monitoring and huge capital investment therefore; they are not categorized as enduring solutions.
Energy conservation techniques help to reduce the consumer demand for long durations [10]. Energy efficiency is a reliable and sustainable solution to deplete the gap between demand and supply. Energy efficient appliances are beneficial for consumers because of less running cost and improved rate of return of initial investment due to savings in electricity bill. The objective of reduced carbon emission could also be achieved with the better management of load through energy efficiency [11]. The major load contributors must be analyzed to make the most appropriate use of energy efficiency and its applications. Many surveys were conducted to find out the major load contributors. The surveys concluded that lighting load contributes from $20 \%$ to $40 \%$ of the total demand for various regions and countries [12]. This leads to the conclusion that if energy efficiency is applied to lighting loads, it can considerably modify the total demand curves. Other energy saving techniques such as day light saving can also reduce the demand and could help towards green building concept $[13,14]$.

A number of efficient lightning schemes have been suggested to effectively reduce the lighting load demand [1517]. Considering the last decade, Compact Florescent Lamp (CFL) has been found as an effective energy efficient tool. Various projects were adopted in Pakistan to promote the use of CFL known as energy savers [18]. Although being energy efficient, it has a low power factor of 0.57 which ultimately increases the system's reactive power demand. Consequently, this results in an increased harmonic level and voltage distortion [19]. Although Light Emitting Diode (LED) seems to be an expensive solution due to its initial cost, it has more advantages over CFL. Yet, LED is an endorsed option because of its efficient performance, ability to curtail the demand, long life and ease of replacement in the existing fixtures [20]. More advancement is required in LED tubes to improve the lighting quality as compared to CFL [21].

In this paper, a LED lighting is presented as a viable option for permanently abridging the total demand. The existing demand and the projected demand using LED have been compared to support the argument. Inferences are made after the application of LED on the monthly demand curves of Pakistan. Section II presents the existing demand and supply situation of Pakistan along with the anticipated demand. The lighting load analysis has been discussed in section III, demonstrating the reduction in consumer demand on monthly basis after having used LED lighting scheme. Section IV 
quantifies how the projected demand will be reduced while section V discusses the area of researches in future. Finally, the paper is concluded in section VI

\section{EXISTING SITUATION OF PAKISTAN}

In order to competently apply energy efficiency in the existing system, it is necessary that the prevailing demand and supply scenario of the country is properly analyzed. The pie chart depicts that the domestic, commercial and industrial sectors form $81 \%$ of the total demand of Pakistan out of which the domestic load shares the maximum percentage i.e. $46 \%$ as can be clearly seen in Figure 1[22]. Thus, application of energy efficiency to this sector would have significant impact.

In 2010-2011, the total generation capacity was $19,000 \mathrm{MW}$ while on the other hand the demand was $24,000 \mathrm{MW}$. This resulted in an enormous shortfall of $5,000 \mathrm{MW}$ as portrayed in Figure 2 [22]. The demand of the country is anticipated to be doubled within a decade as shown in Figure 3 [23, 24]. This figure also shows that in the year 2030 the projected demand would become $113,695 \mathrm{MW}$, which would ultimately require a humungous amount of capital investment to meet the consumer demands [25]. This is a thoughtful dilemma for a Pakistan because the country is seriously deficient in generation capacity. Increasing the generation capacity would have a direct adverse impact on the environment because of the increased emissions of GHGs [3].

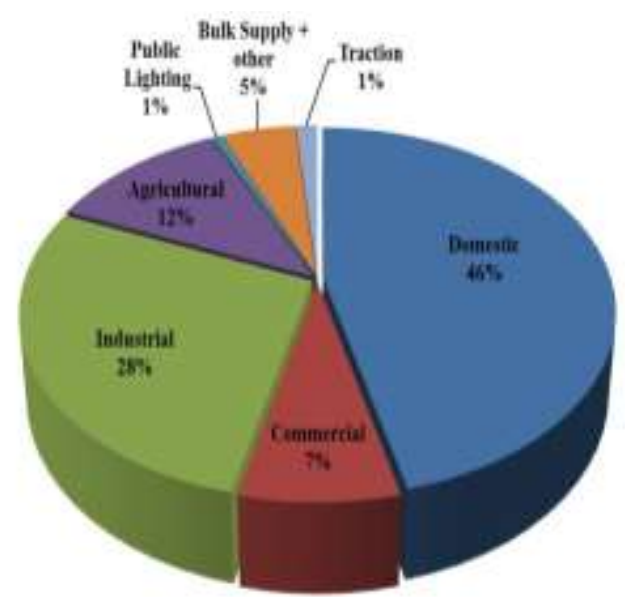

Fig. 1. Sector Wise Electricity Share in Pakistan

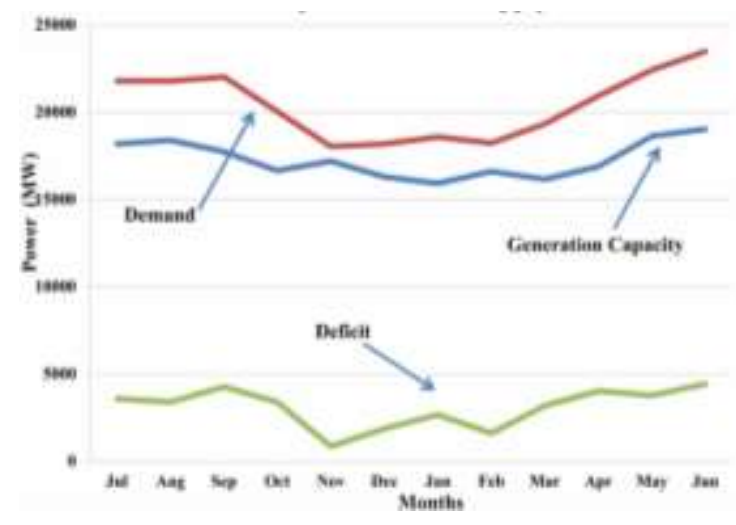

Fig. 2. Monthly Electricity Demand and Supply Curve of Pakistan

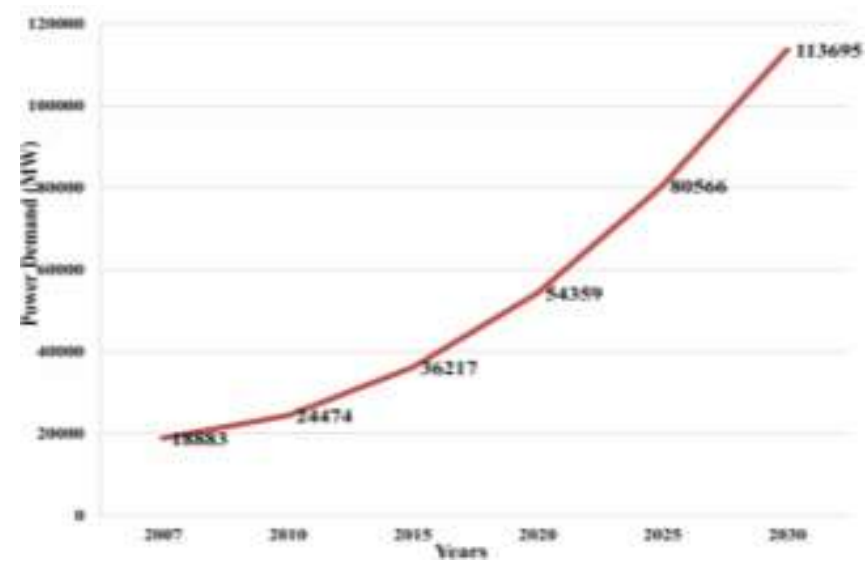

Fig. 3. Projected Power Demand of Pakistan

\section{LIGHTING LOAD ANALYSIS}

An extensive research on electrical loads needs to be carried out throughout the country, in order to analyze the potential electrical loads for energy efficiency considerations. To serve the purpose, a thorough research on lighting load was conducted in Pakistan to explore the scale of energy efficiency through the application of modern lighting. The data has been collected by carrying out surveys, energy audits, building design projects, lighting projects in various companies, survey from students in order to gain the data for industrial, commercial as well as residential lighting loads. Similar initiatives can be taken for cooling, heating, motoring and other loads, to estimate the magnitude of energy conservation in these areas.

It should be noted that the lighting load adds up to $83 \%$ of the combined demand of the industrial, domestic and commercial sectors as can be seen in Figure 4. The commercial sector contributes to the greatest percentage of lighting load i.e. $40 \%$ as can be observed in Table I. Hence, it provides greater opportunities than any other sector to implement energy efficiency and conservation schemes. The load research also led to the conclusion that lighting load shares $19.6 \%$ of the total demand of the country (see Table II) which is comparable to United Kingdom and other countries [10]. According to lighting load research, Magnetic Blast Compact Fluorescent Lights (MCFLs) are the most used lighting schemes in domestic, commercial and industrial sectors as can be observed in Table III. Thus, MCFLs can be replaced by LED in order to conserve a significant amount of energy.

Here some abbreviations are used in Table III and Table IV to represent the following lamps.

$\mathrm{CFL}=$ Compact Florescent Lamp

$\mathrm{ECFL}=$ Electronic blast Compact Florescent Lamp

MCFL = Magnetic blast Compact Florescent lamp

$\mathrm{IL}=$ Incandescent Lamp

$\mathrm{MH}=$ Metal Halide

LED $=$ Light Emitting Diode 
TABLE I DATA SUMMARY OF AUDITED BUILDINGS

\begin{tabular}{|l|c|c|c|}
\hline \multicolumn{1}{|c|}{ Sector } & Audit Load (MW) & Lighting Load (MW) & LL \\
\hline Domestic & 5.18 & 1.036 & $20 \%$ \\
\hline Commercial & 2.72 & 1.112 & $40 \%$ \\
\hline Industrial & 161.9 & 12.95 & $8 \%$ \\
\hline Agricultural & 2.12 & 0.297 & $14 \%$ \\
\hline
\end{tabular}

TABLE II SECTOR WiSE LIGHTING LOAD IN PAKISTAN

\begin{tabular}{|l|r|r|r|r|r|}
\hline \multicolumn{1}{|c|}{ Sector } & \multicolumn{1}{c|}{$\begin{array}{c}\text { Power } \\
\text { Demand } \\
\text { MW }\end{array}$} & $\begin{array}{c}\text { Annual } \\
\text { GWh }\end{array}$ & \multicolumn{1}{c|}{$\begin{array}{c}\text { Lighting } \\
\text { load } \\
\text { Percentage }\end{array}$} & $\begin{array}{c}\text { Lighting } \\
\text { load in } \\
\text { MW }\end{array}$ & $\begin{array}{c}\text { Annual } \\
\text { GWh of } \\
\text { lighting }\end{array}$ \\
\hline Domestic & 10747 & 35,229 & $20 \%$ & 2149.4 & 7045.8 \\
\hline Commercial & 1752.3 & 5,725 & $40 \%$ & 700.92 & 2290 \\
\hline Industrial & 6476 & 21,146 & $16 \%$ & 1036.16 & 3383.36 \\
\hline Agricultural & 2747.61 & 8,972 & $14 \%$ & 384.67 & 1256.08 \\
\hline $\begin{array}{l}\text { Public } \\
\text { Lighting }\end{array}$ & 133.17 & 435 & $100 \%$ & 133.17 & 435 \\
\hline $\begin{array}{l}\text { Bulk Supply } \\
+ \text { other }\end{array}$ & 1137.83 & 3,690 & $15 \%$ & 170.67 & 553.5 \\
\hline Traction & 331.76 & 1,087 & & & - \\
\hline Total & 23325.67 & 78720 & $19.61 \%$ & 4574.99 & 14963.7 \\
\hline
\end{tabular}

TABLE III LAMP WISE LIGHTING LOAD (IN MW) OF PAKISTAN

\begin{tabular}{|c|c|c|c|c|c|c|c|}
\hline 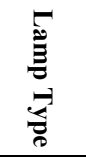 & 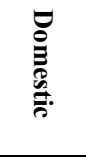 & 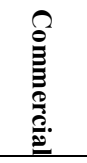 & 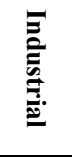 & 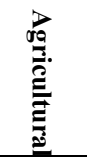 & 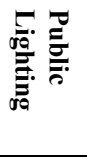 & 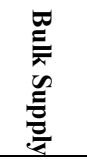 & $\overrightarrow{0}$ \\
\hline CFL & 623.3 & 266.3 & 86.3 & 134.6 & & 46.1 & 1156.7 \\
\hline ECFL & 214.9 & 28.0 & 59.3 & 19.2 & & 13.7 & 335.2 \\
\hline MCFL & 752.3 & 210.3 & 242.8 & 96.2 & 5.3 & 63.1 & 1370.0 \\
\hline IL & 343.9 & 140.2 & 5.4 & 76.9 & & 17.1 & 583.5 \\
\hline MH & 129.0 & 49.1 & 107.9 & 19.2 & 13.3 & 23.9 & 342.4 \\
\hline LED & 21.5 & 7.0 & 10.8 & 0.0 & & 3.4 & 42.7 \\
\hline Others & 64.5 & 7.0 & 27.0 & 38.5 & 115.9 & 3.4 & 256.2 \\
\hline Total & 2149.4 & 700.92 & 539.5 & 384.67 & 133.17 & 170.67 & 4078.3 \\
\hline
\end{tabular}

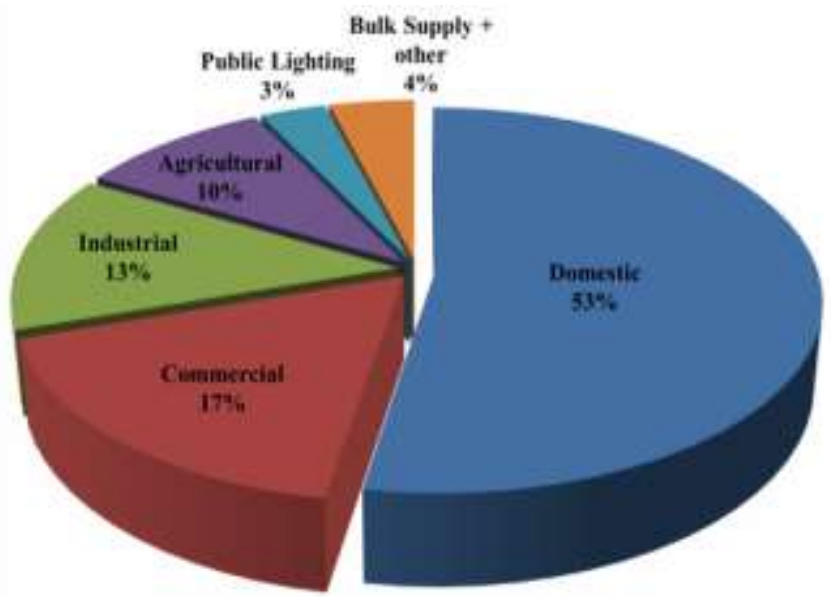

Fig. 4. Sector wise Lighting Load Share of Pakistan

\section{IMPACT OF LED Lighting ON MONTHLY DEMAND}

The contributions of lighting load in different sectors of the country have been summed up in Table III. Monthly lighting load power demand can be reduced up to $62 \%$ when the existing lighting schemes would be replaced by LEDs as quantified from Table IV. The proposed stratagem would reduce the demand from $23,325 \mathrm{MW}$ to $19,624 \mathrm{MW}$ which is a noticeable reduction. Approximately $850 \mathrm{MW}$ of power demanded is expected to be saved as can be seen in Figure 5. This demand reduction is equivalent to a large power plant. The expected deficit curve using LED is far below the current deficit curve. The power savings shown in Figure 6 are expected to be achieved with the use of LED lighting scheme. This technique will result in a lasting reduction in the demand and will yield permanent profits to the utility company. The suggested scheme will have a positive impact on reduction of lighting load by considerably lowering the electricity demand in various sectors.

This demand reduction would be more meaningful for projected power demand and approximately 12000MW of demand could be reduced in 2030 as shown in Figure 7. Power planning has become very essential to overcome the mitigation and other associated problems in 2030.

TABLE IV. LAMP TYPE AND CONSERVATION FACTORS

\begin{tabular}{|c|c|c|c|}
\hline $\begin{array}{l}\text { Lamp } \\
\text { Type }\end{array}$ & $\begin{array}{l}\text { Power } \\
\text { Consumption } \\
\text { MW }\end{array}$ & $\begin{array}{l}\text { \% Saving } \\
\text { from } \\
\text { LED }\end{array}$ & $\begin{array}{l}\text { Demand } \\
\text { Reduction } \\
\text { MW }\end{array}$ \\
\hline CFL & 1156.711 & $45 \%$ & 520.52 \\
\hline ECFL & 335.2089 & $50 \%$ & 167.6045 \\
\hline MCFL & 1369.983 & $70 \%$ & 958.9882 \\
\hline IL & 583.484 & $87 \%$ & 507.6311 \\
\hline $\mathrm{MH}$ & 342.3727 & $70 \%$ & 239.6609 \\
\hline LED & 42.7066 & $0 \%$ & 0 \\
\hline \multirow[t]{2}{*}{ Others } & 256.2045 & $50 \%$ & 128.1023 \\
\hline & 4078.281 & 0.62 & 2522.507 \\
\hline
\end{tabular}

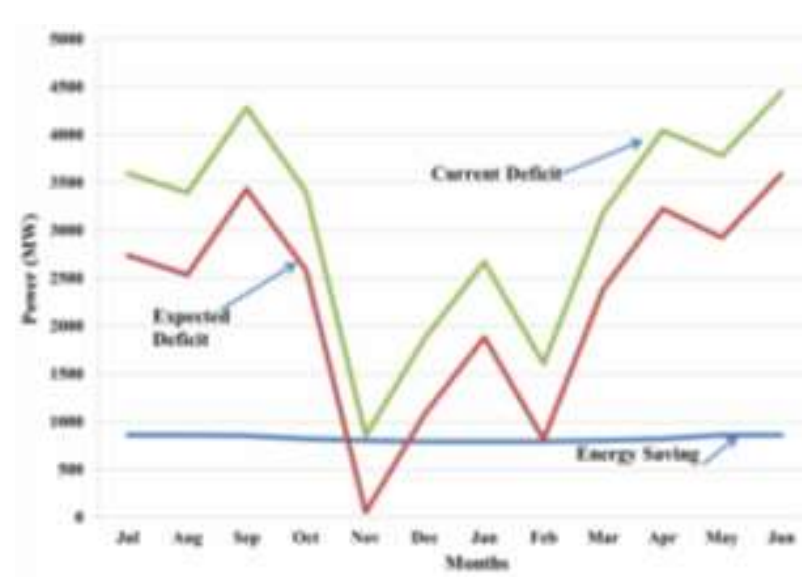

Fig. 5. Comparison of Existing and Expected Deficit 


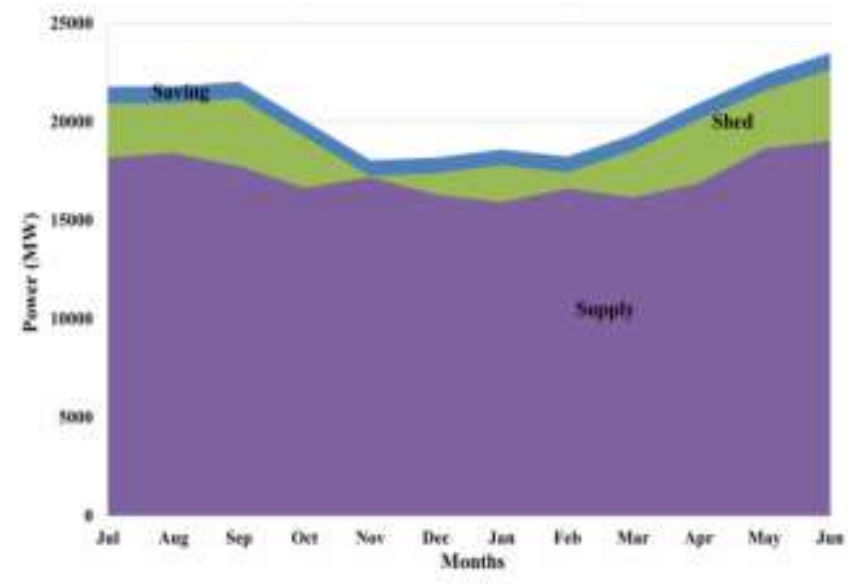

Fig. 6. Expected Demand and Supply Curve with LED

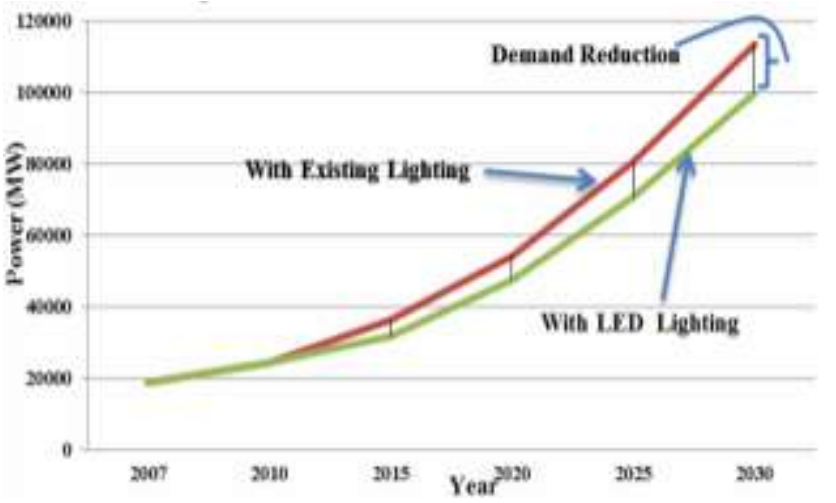

Fig. 7. Projected Power Demand of Pakistan with LED

\section{RECOMMENDATIONS}

For the implementation of this scheme, it is required to take initiatives on global level to promote the use of LED. If the implementation of this energy efficiency scheme is properly executed it will take only a few years for the commercial, industrial and domestic sectors to completely shift their lighting loads to LED lighting. Energy awareness programs should be designed to motivate the consumers for actively participating in the energy conservation schemes. Adequate incentives should be provided to the manufacturing companies to initiate a healthy competition in the manufacture of LEDs. Government can also take initiatives to subsidize the cost of LED's and hence make it more affordable and within reach for the common man. Research on energy efficiency and energy conservation techniques must be carried on and other areas having potential for energy conservation should be explored. This can be achieved by designing policies, carrying out audits and developing standards for annual load research.

\section{CONCLUSION}

In this paper, technical aspects of LED lighting scheme have been summarized using collected data from various industries and surveys. The implementation of LED lighting has resulted in a significant reduction of $2522.5 \mathrm{MW}$ which is equal to a large power plant. This demand reduction is $62 \%$ of the total lighting loads which is equivalent to $10.5 \%$ of total demand of Pakistan. It is summed up that the power companies will be able to bridge the gap between the power demand and supply without taking any further time delay in setting up of generation plants.

The research motivates the government bodies, policy makers and stake holders to promote the use of LED lighting scheme to overcome load shedding and environmental challenges. Pakistan and other energy starving countries are encouraged to adopt this conservation scheme to save this planet from harmful effects of greenhouse gases.

\section{ACKNOWLEDGMENT}

Author Junaid A. Qureshi would like to acknowledge M/S MIQ Energy, M/S Natural Reflection Energy Solutions Company and other sister companies for sharing their project details. We also would like to acknowledge the students of Electrical Engineering Department of NED University of Engineering and Technology Karachi for providing complete load details of their homes.

\section{REFERENCES}

[1] 2013; Available from:

http://practicalaction.org/docs/advocacy/energypovert yhiddencrisis.pdf.

[2] LOUIS, V.L.S., et al., Reservoir surfaces as sources of greenhouse gases to the atmosphere: A global estimate. BioScience, 2000.

50(9): p. 766-775.

[3] Ooi, R.E.H., D.C.Y. Foo, and R.R. Tan. Multi period planning on grid-wide carbon sequestration retrofit in power generation sector with pinch analysis. in 4th International Conference on Modeling, Simulation and Applied Optimization (ICMSAO), 2011

[4]

$$
\text { 2013. Available from: }
$$

http://www.maverickpakistanis.com/2010/04/pakis tan-electricity- shortfall-reaches-mammoth$6000 \mathrm{mw} /$.

[5] Violent protests continue against power loadsheddin in Punjab. The News 01 june 2012 [cited 2012 6th Oct]; Available from:

http://www.thenews.com.pk/Todays-News-135029-Violent-protests-continue-against-powerloadshedding-in-Punjab.

[6] Qureshi, W.A., N.-K.C. Nair, and M.M. Farid, Impact of energy storage in buildings on electricity demand side management. Energy Conversion and Management, 2011. 52(5): p. 2110-2120.

[7] Garrido-Soriano, N., et al., Potential energy savings and economic impact of residential buildings under 
national and regional efficiency scenarios. A Catalan case study. Energy and Buildings.

49(0): p. 119-125.

[8] Qureshi, J.A., M. Gul, and W.A. Qureshi. Demand Side Management through innovative load control. in IEEE Region 10 Conference-TENCON' 10. 2010 .

[9] Qureshi, J.A., M. Gul, and W.A. Qureshi, Intelligent Demand Management for End User Benefits, in Innovative Smart Grid technologies 2011. 2011, IEEE PES: Jeddah, Saudia Arabia.

[10] Saidur, R., Energy consumption, energy savings, and emission analysis in Malaysian office buildings. Energy Policy, 2009.37(10): p. 4104-4113.

[11] Worrell, E., L. Price, and N. Martin, Energy efficiency and carbon dioxide emissions reduction opportunities in the US iron and steel sector. Energy, 2001. 26(5): p. $513-536$

[12] Dhingra, A. and T. Singh, Energy Conservation with Energy Efficient Lighting. WSEAS Transactions on Environment and Development, (10): p. 630-639.

[13] Yun, G.Y., H. Kim, and J.T. Kim, Effects of occupancy and lighting use patterns on lighting energy consumption. Energy and Buildings. 46(0): p. 152-158.

[14] Shin, J.Y., G.Y. Yun, and J.T. Kim, View types and luminance effects on discomfort glare assessment from windows. Energy and Buildings. 46(0): p. 139-145.

[15] Elwell, B.E., Fully automatic energy efficient lighting control and method of making same. 1994, Google Patents.

[16] Martinot, E. and N. Borg, Energy-efficient lighting programs: experience and lessons from eight countries. Energy Policy, 1998.26(14): p. 1071-1081.

[17] Li, D.H., et al., An analysis of energy-efficient light fittings and lighting controls. Applied Energy, 2010. 87(2): p. 558-567.

[18] Use of CFL can save up to 1100MW. 09 Dec 2009 [cited 2012 6th July]; Available from: http://paktribune.com/business/news/Use-of-CFLcan-save-up-to-1100MW-6564.html.

[19] Duff, J.T., An Examination Into the Use of Compact Fluorescent Lamps in the Domestic Environment. Journal of Sustainable Engineering Design, 2012. 1(1): p. 7.

[20] Mustafa, G.K., V.T. Rouf, and J. Khisha. Feasible lighting system with light emitting diode(LED). in
International Conference on Electrical Engineering/Electronics Computer Telecommunications and Information Technology (ECTI-CON), 2010.

[21] Ryckaert, W.R., et al., Linear LED tubes versus fluorescent lamps: An evaluation. Energy and Buildings. 49(0): p. 429-436.

[22] NEPRA. State of Industry Report,Pakistan. 2013 [cited 2014 10th July]; Available from: http://www.nepra.org.pk/Publications/State\%20of\% 20Industry\%20Reports/State $\% 20$ of $\% 20$ Industry $\% 20$ Report\%202013.pdf.

[23] Profiles, C.N.P., International Atomic Energy Agency (IAEA). 2000, October.

[24] Suganthi, L. and A.A. Samuel, Energy models for demand forecastingâ€"A review. Renewable and Sustainable Energy Reviews. 16(2): p. 1223-1240.

[25] CO2 emissions from fuel combustion. International Energy Agency Statistics 2011 [cited 2012 10th July]; Available from: http://www.iea.org/CO2highlights/CO2highlights.pd f. 